\title{
AN EFFECTIVE ASSESSMENT OF DEEN DAYAL UPADHYAY GRAMEEN KAUSHALYA YOJANA (DDU-GKY) IN PROVIDING SKILL TRAINING PROGRAMME FOR YOUTH: A STUDY OF HARYANA STATE
}

\author{
${ }^{1}$ Vaibhav Verma, ${ }^{2}$ Dr. Pradeep Singh Chauhan \\ ${ }^{1}$ Research Scholar, Department of Economics Kurukshetra University Kurukshetra \\ ${ }^{2}$ Associate Prof. Department of Economics IIHS, Kurukshetra University Kurukshetra
}

Article DOI: https://doi.org/10.36713/epra7381

DOI No: 10.36713/epra7381

\begin{abstract}
Skills development is imperative to sustaining traditional growth and development in a country like India which is experiencing a demographic dividend. It is a huge challenge not only for the government, but also for the private sector and educational institutions to rise up and specialize to make the country's youth employable and ensure that there is no mismatch between demand and the offer. This study examines the role of Deen Dayal Upadhyay Grameen Kaushalya Vikas Yojana (DDU-GKY) in the development of rural youth in the Haryana State. Secondary data (2015-2021) were used for the study. The results show that the interest of the population towards DDU-GKY and the interns recruited has greatly diminished, which is a matter of concern.
\end{abstract}

KEY WORDS: Demographic Dividend, Inclusive Growth, Smart Cities, Skill India

\section{INTRODUCTION}

India has started to evolve on the world platform due to its dynamic and rapid growth in its gross domestic product. However, this GDP growth lacked inclusiveness in its growth process, which raised major issues such as unemployment, poverty and inequality over the same period. While the eleventh five-year plan (2007-2012) introduced "inclusive growth" as a main objective, so did the main objective of the twelfth fiveyear plan (2012-2017). To promote inclusive growth, the government should intervene by implementing various public programs at the micro and macro levels, including job creation, infrastructure development, improving access to quality education and healthcare services.

The current pandemic and economic downturn again raise questions about the major challenges of job creation, especially why the Indian economy has not been faster in generating more productive jobs. On the other hand, the increase in the size of the population and the large shifts in migration from rural to urban areas have worsened the housing situation in urban areas of India, where large numbers of people do not have adequate accommodation with basic amenities. Large number of India's poor remain in rural areas. Many of these people work in casual labor markets in both agricultural and non-agricultural sectors in which there is little return on labor market skills and experience, and where incomes are therefore limited by the marginal product of labor manual work. Given the overall supply and demand conditions, the return on this work may not generate sufficient household income for a household with non-working dependents to exceed the poverty line. While a system of transfers to low-income households can reduce poverty at least in the short term, such transfers place a heavy burden on state budgets and may prevent the state from making productive investments in public resources that lead to long-term sustainable growth and development. On this basis, it would seem desirable to better understand the nature of rural income growth with a view to how best to promote well-paid jobs. Over the last three-and-a- 
half decades, there has been a structural shift in the occupational choice among rural workers, particularly rural agricultural workers, with changes in their occupational choices ranging from agriculture to nonagricultural sectors. According to the 38th Round (1983) of the National Sample Survey (NSS) report, around 77 percent of rural households depend on the agricultural sector to sustain their livelihoods. Rural households' dependency on agriculture has declined to 50 percent as per the latest round of the Periodic Labour Force Survey (PLFS) for 2018-19. The primary reasons behind the decline in employment opportunity in the rural area are insufficient public investment for agrarian development, inadequate access to institutional credit, inadequate irrigation facilities, government's poor agriculture-related marketing policies, half-baked land reform policy, and low return from agriculture are responsible for the fall in agricultural employment.

Haryana has recorded the highest unemployment rate in the country, as per the data released by the Centre for Monitoring Indian Economy for June 2021. With a $29.1 \%$ unemployment rate, Haryana's unemployment is nearly 2.5 times the national average $12.6 \%$. Despite being a largely agrarian state, employment opportunities for the state's youth in the agricultural sector have declined over time. Rising up to the formidable task of finding gainful employment for the youth of Haryana, who were traditionally engaged in agricultural activities, is to formulate the right policy to ensure stable employment. The slowing economy and shortage of new jobs prompted the northern state of Haryana, where Gurugram is located, to implement a new law last month that bans private companies from hiring workers of other states. Still, there is a serious topic of skill development because it is very difficult to get a job in these national and multi-national companies without it. Deen Dayal Upadhyaya Grameen Kaushalya Yojana (DDU-GKY) is uniquely focused on rural youth between the ages of 15 and 35 years from poor families.

\section{OBJECTIVE OF THE STUDY}

1. Role of skill development training program in youth, Haryana.

2. To get an overview of Deen Dayal Upadhyaya Kaushalya Yojana.

3. Find out employment achievement through DDU-GKY in Haryana based on 2015 to 2021 data.

\section{LITERATURE REVIEW}

Chizoba, Chitom \& Uju (2020) examined the effect of skills acquisition on youth employability in Nigeria. The results of the study show that the problems faced by young people in acquiring skills in Nigeria are the lack of qualified trainers, lack of facilities, insufficient funding and weaker government monitoring. The results of the study also indicate that entrepreneurial training or skills acquisition has reduced unemployment and crime rates and is the cause of economic growth and development.

Agrawal \& Thakur (2019) found the impact of Pradhan Mantri Kaushalya Vikas Yojana on youth productivity in the Gwalior region. The research results show that the training methods and activities brought new abilities to the trainees while performing a task and resulted in an increase in productivity. Increased productivity is helpful in earning more livelihoods, promoting them for entrepreneurship and solving their unemployment problem

Dewangan (2018) in his article on "Empowering rural youth through Pradhan Mantri Kaushalya Vikas Yojana" described skills development initiatives in rural areas of the country. The aim of this study is to describe the role and main characteristics of Pradhan Mantri Kaushalya Vikas Yojana and his contribution to the empowerment of the rural youth population.

Pandey and Nema (2017), in their article on "Impact of skill India training program among young people", pointed out that a maximum number of young people in the country lack knowledge and expertise in the use of modern technologies. Skills development The program is, therefore, a powerful weapon through which young people can be technically trained to survive in this technological age. Through such programs, young people can also be motivated by entrepreneurship to start their own business. But the existing skills development programs in the country face some challenges such as strong competition in the market for their own work, subsidies to start a new business, lack of awareness related to various policies underway for their workers. advantages and shortage of raw materials.

Shrivastav \& Jatav (2017) revealed how the different types of programs launched by the Indian government can generate employment opportunities in India with new demands for industrial skills. The study concludes on the general state of available skills capacities, requirements, gaps and initiatives undertaken by the Indian government for skills development. There is an immediate need for therapy for the current skills development strategy in India. 
Aggarwal (2016) in his article on "Skills development in India" analyzed the skills development process in India from different angles. The study concluded that in addition to focusing on the quantitative aspect of skilled labor, policymakers should also focus on the qualitative aspect of skills development programs. The current situation requires the country to India to improve the quality of ITIs and work with the private sector to move beyond digital vocational training targets to improve apprenticeship programs.

Sharma and Sethi (2015), through their article on "Skill Development: Opportunities \& Challenges in India", attempted to analyze the gap between existing demand and the supply of skilled labor. Their findings clearly show that India will face the major challenge of closing the skills gap over the coming decades. The skills gap can have a serious impact, not only on employers, but also on the economy as a whole. One of the main concerns is the loss of productivity and income, as many jobs remain vacant for a long time due to the lack of skilled labor. The study highlights how serious it is for government and other stakeholders to work together to create a skilled workforce to fill the skills gap and boost economic growth.

Kanchan \& Varshney (2015), reported in their research paper on the impact of skills development strategies and initiatives in India. A study based on secondary data sources found that 80 percent of India's rural and urban workforce have low marketable skills. The study reveals that filling this gap with various skills development initiatives results in a skilled workforce to cope with the global hub.

Kedar (2015), India's labor productivity is lower than that of Asian economies and requires upgrading the skills of the labor force to ensure economic growth.

\section{METHODOLOGY}

The study is based on a review of the literature and secondary data, which includes various articles, circulars, and reports from MoRD, CMIE, and census reports.

\section{DDU-GKY}

The Ministry of Rural Development (MoRD) announced the Deen Dayal Upadhyaya Grameen Kaushalya Yojana (DDU-GKY) Antyodaya Diwas, on 25th September 2014. DDU-GKY is a part of the National Rural Livelihood Mission (NRLM), tasked with the dual objectives of adding diversity to the incomes of rural poor families and cater to the career aspirations of rural youth. DDU-GKY is uniquely focused on rural youth between the ages of 15 and 35 years from poor families. As a part of the Skill India campaign, it plays an instrumental role in supporting the social and economic programs of the government like the Make In India, Digital India, Smart Cities and Start-Up India, Stand-Up India campaigns. Over 180 million or $69 \%$ of the country's youth population between the ages of 18 and 34 years, live in its rural areas. Of these, the bottom of the pyramid youth from poor families with no or marginal employment number about 55 million. At present, this scheme is being operated in 27 states and 3 union territories. Under this scheme, there are 2198 training centers, 1822 projects, 839 project implementing agencies are providing training in 56 sectors and there are more than 600 job roles.

During the year 2020-21, 28687 beneficiaries were provided training and 49396 candidates have been given placements till 31 March 2021. From the date of launch of this scheme till 31st March 2021, about 10.81 lakh candidates have been trained in 56 sectors and 600 trades and 6.92 lakh candidates have been provided placements.

DDU-GKY Mission: 1. Reduce poverty by enabling poor households to access remunerative and sustainable employment through employment that provides a regular salary. 2. Diversify the income of poor rural families. 3. Cater to the professional aspirations of rural youth. (MoRD, 2016)

Implementation Model under DDU-GKY: Each state has a special role in implementing the DDU-GKY program. States have full power to assess, approve and guide the program in their states after they achieve Annual Action Plan (AAP) status. The States manages fund releasing. DDU-GKY follows a 3-tier implementation model. The DDU-GKY National Unit at MoRD functions as the policy-making, technical support, and facilitation agency. The DDU-GKY State Missions provide implementation support, and the Project Implementing Agencies implement the program through skilling and placement projects. (MoRD,2016)

Project Funding of DDU-GKY: DDU-GKY provides financial support for placement skills projects that meet market demand with financial support ranging from Rs. 25,696 to over Rs. 1 lakh per person, depending on the duration of the project and whether the project is residential or non-residential. DDU-GKY finances projects with a training duration of 576 hours (3 months) to 2304 hours (12 months). Funding elements include support for training, board and lodging costs (residential programs), transportation costs, post-placement support costs, career progression and retention support costs. DDU-GKY funds a variety of vocational training programs covering over 250 trades in various industries such as retail, hospitality, 
healthcare, construction, automotive, leather, electrical, plumbing, gemstones and jewelry, to name a few. The only mandate is that vocational training be demanddriven and lead to the placement of at least $75 \%$ of trainees.

Courses offered under DDU-GKY: DDU-GKY mandates two types of training in every course Generic
Training on Soft Skills, English and Information Technology (ii) Trade Specific Skills with a minimum duration of hours with different structured of duration 3 months, 6 months, 9 months \& 12 months, the duration for which are 576 hours, 1152 hours, 1728 hours and 2304 hours respectively.

Table1: Courses offered under DDU-GKY

\begin{tabular}{|l|c|c|c|c|}
\hline \multirow{2}{*}{ Subject } & \multicolumn{3}{|c|}{ Minimum Training Duration in Hours } \\
\cline { 2 - 5 } & For 3 month & For 6 month & For 9 month & $\begin{array}{c}\text { For 12 } \\
\text { month }\end{array}$ \\
\cline { 2 - 5 } & Course & Course & Course & Course \\
\hline English & 60 & 120 & 180 & 240 \\
\hline Soft Skills & 20 & 40 & 60 & 80 \\
\hline Computer & 80 & 160 & 240 & 320 \\
\hline $\begin{array}{l}\text { Trade Specific Training with or } \\
\text { without 0JT }\end{array}$ & 416 & 832 & 1248 & 1664 \\
\hline Total & & & & \\
\hline
\end{tabular}

Source: http://ddugky.gov.in/

The training plan can also provide for on-the-job training (OJT) as part of the training module, which cannot exceed 30 days for 3-month training, 60 days for 6-month training, 90 days for a 9-month training course. course, and 30 days for a one-year course

\section{Analysis and Interpretation}

In Haryana, Deen Dayal Upadhyaya - Grameen Kaushalya Yojana (DDU-GKY) is operated through Haryana State Rural Livelihood Mission (HSRLM). Society works for the empowerment of the poor and poverty reduction by focusing on the livelihood of the poor and weaker sections of the society in rural areas. It aims to empower poor families to remove all social, economic, cultural, and psychological barriers by promoting institutions of the poor at various levels. An environment conducive to the realization of the full potential and inherent capabilities of the poor will be created through social mobilization - creating and promoting opportunities for the poor. Society has to work to enable the poor people to understand the possibilities of change and bring about the desired change by collective action and participation of the poor in implementation. The district wise target assigned and the total project of this program in Haryana are as follows

Table 2: DDU-GKY Approved Projects

\begin{tabular}{|c|c|c|c|}
\hline Sr No. & District Name & Total Project & Total Target Assigned \\
\hline $\mathbf{1}$ & Ambala & 4 & 14600 \\
\hline $\mathbf{2}$ & Bhiwani & 8 & 32470 \\
\hline $\mathbf{3}$ & Faridabad & 5 & 13045 \\
\hline $\mathbf{4}$ & Fatehabad & 2 & 15660 \\
\hline $\mathbf{5}$ & Gurgaon & 4 & 12245 \\
\hline $\mathbf{6}$ & Hisar & 3 & 17285 \\
\hline $\mathbf{7}$ & Jhajjar & 5 & 20105 \\
\hline $\mathbf{8}$ & Jind & 3 & 13800 \\
\hline $\mathbf{9}$ & Kaithal & 2 & 15660 \\
\hline $\mathbf{1 0}$ & Karnal & 3 & 16260 \\
\hline $\mathbf{1 1}$ & Kurukshetra & 3 & 18260 \\
\hline
\end{tabular}




\begin{tabular}{|c|c|c|c|}
\hline $\mathbf{1 2}$ & Mahendragarh & 2 & 10860 \\
\hline $\mathbf{1 3}$ & Mewat & 3 & 10600 \\
\hline $\mathbf{1 4}$ & Palwal & 1 & 2000 \\
\hline $\mathbf{1 5}$ & Panchkula & 4 & 18105 \\
\hline $\mathbf{1 6}$ & Panipat & 3 & 12400 \\
\hline $\mathbf{1 7}$ & Rewari & 2 & 9860 \\
\hline $\mathbf{1 8}$ & Rohtak & 4 & 13400 \\
\hline $\mathbf{1 9}$ & Sirsa & 2 & 15660 \\
\hline $\mathbf{2 0}$ & Sonipat & 3 & 12400 \\
\hline $\mathbf{2 1}$ & Yamunanagar & 2 & 10400 \\
\hline
\end{tabular}

Source: http://ddugky.gov.in/

Table 3: Status of DDU-GKY in Haryana 2015 - 2021 (Till 06 June 2021)

\begin{tabular}{|l|c|c|c|c|c|c|}
\hline Year & Commenced & Trained & Placed & Assessed & Certified & $\begin{array}{c}\text { Overall } \\
\text { Target(Till } \\
\text { March 2022) }\end{array}$ \\
\hline $\mathbf{2 0 1 5 - 1 6}$ & 13,986 & 12,420 & 737 & 10,936 & 4,179 & 66,330 \\
\hline $\mathbf{2 0 1 6 - 1 7}$ & 10,121 & 10,714 & 1,559 & 8,555 & 3,008 & 66,330 \\
\hline $\mathbf{2 0 1 7 - 1 8}$ & 2,285 & 2,904 & 3,913 & 1,731 & 890 & 66,330 \\
\hline $\mathbf{2 0 1 8 - 1 9}$ & 3,237 & 1,712 & 3,329 & 1,452 & 1,148 & 66,330 \\
\hline $\mathbf{2 0 1 9 - 2 0}$ & 1,768 & 1,948 & 6,013 & 1,100 & 773 & 66,330 \\
\hline $\mathbf{2 0 2 0 - 2 1}$ & 877 & 26 & 1,213 & 11 & 6 & 66,330 \\
\hline $\mathbf{2 0 2 1 - 2 2}$ & 150 & 0 & 0 & 0 & 0 & 66,330 \\
\hline
\end{tabular}

Source: https://Kaushalyapragati.nic.in/* Till June 2021

The above table shows that 2015 to 2021 total 32,424 commenced training, in that 29724 trainees completed training $(91.67 \%)$. Total trained persons were $29724(91.67 \%)$ but placed only 16764
(56.39\%). This shows that the interest of the people towards DDU-GKY and recruited trainees have decreased a lot which is a matter of concern.

Figure 1: Status of DDU-GKY in Haryana 2015 - 2021 (Till 06 June 2021)

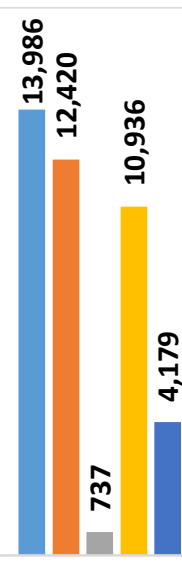

2015-16

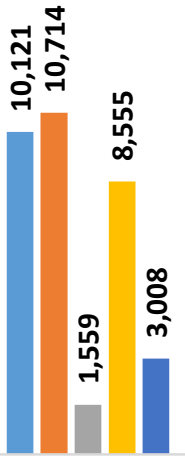

2016-17

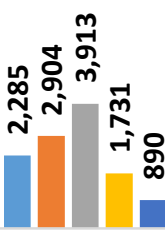

2017-18

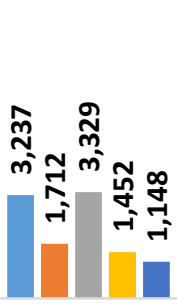

2018-19

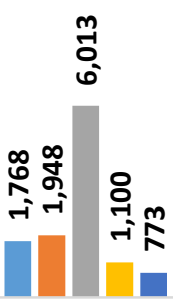

2019-20

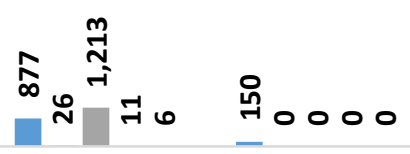

2020-21

2021-22 


\section{Drawbacks of the DDU-GKY Training Program}

Rural youth who have never worked in the formal sector face many challenges in finding and keeping a job. There are many challenges that affect the recipient's ability to maintain employment or to maintain sustainable employment. These problems exist not only in the workplace but also outside the workplace due to a candidate's poor economic situation and different socio-cultural background as DDU-GKY candidates come from the rural hinterland of Haryana state. There are very specific and people-centered challenges that increase the vulnerability of newly employed rural youth in the workplace. The nature of the problems also depends on trade and geography. For example

- Problem immobilization

- Study gap of trainees after 10th or plus two

- Adjustment problems of trainees

- Family issues

- Health issues

- Not willing to do the job after the free training period.

- Skill mismatch according to industry.

- Low salary

\section{SUGGESTIONS}

The imperative of skills development to support the growth and development of the general public is often overlooked and put on the back burner and still viewed as a non-scalable model due to the high capital required and low return on investment. It is a huge challenge not only for the government but also for the private sector and educational institutions to rise up and specialize to make young people employable and ensure that there is no mismatch between demand and supply. They should also focus on the increased use of modern technology in the workplace/assembly line. In addition, there is a mismatch between the aspirations of young people and the jobs available. Eg. The construction sector generally employs migrant workers from other states.

- Awareness creation about skill training programs

- An aptitude test is needed before training

- Need-based training programs

- Counseling

- Conduct Recreation activities

- Increase training centers

\section{CONCLUSION}

The Indian government is offering a skills development program for the nation's youth by implementing Deen Dayal Upadhyaya Kaushalya Yojana (DDU-GKY). This vocational training and placement program of the Ministry of Rural Development (MoRD). Based on secondary data of Haryana state, it appears that more people come forward to attend such training programs, but interns' placements are very few. So the awareness programs on various skills development programs are very essential in our society and the salary after training needs to increase.

\section{REFERENCES}

1. Agrawal, M., \& Thakur, K. S. (2019). Impact of Pradhan Mantri Kaushalya Vikas Yojana on the Productivity of Youth in Gwalior Region, India. International Journal of Recent Technology and Engineering (IJRTE), 8 (4), 801 806

2. Agrawal, P. Skill Development in India. (2016) International Journal of Engineering Technology, Management, and Applied Sciences. 4 (9): 160-166

3. Chizoba, O., Chitom, J.-A., \& Uju, M. (2020). Effect of Skill Development on Youth Employability in Nigeria. International Journal of Research in Finance and Management, 3 (1), 33-37.

4. Dewangan, R. (2018). Empowering Rural Youth through Pradhan Mantri Kaushalya Vikas Yojana (PMKVY). International Journal of Basic and Applied Research, 8 (8), 945-951.

5. Kanchan, S., \& Varshney, S. (2015). Skill development initiatives and strategies. Asian Journal of Management Research, 5(4), 666-672.

6. Kedar, M.S. (2015). Skill Development in India Challenges and Opportunity. International Research Journal of Multidisciplinary Studies 1(5).

7. MoRD. (2016). Deen Dayal Upadhya Gramin Kaushalya Yojana.

8. Pandey A, Nema D.K. (2017). Impact of Skill India Training Program among the Youth. International Journal of Multidisciplinary Research and Development. 4 (7): 294-299

9. Sharma E, Sethi S. (2015) Skill Development: Opportunities \& Challenges in India. Gian Jyoti EJournal. 5(1): 45-55.

10. Shrivastav, R. K. \& Jatav, A. (2017). An Analysis of Benefits and Challenges of Skilling India. 9th International conference on science, technology, and management, Indian Federation of United Nations Association, New Delhi, ISBN: 9789386171719. Retrieved from http://conferenceworld.in. 


\section{WEBSITE}

1. http://ddugky.gov.in

2. http://ddugky.gov.in/content/state-skill development-missions

3. https://Kaushalyapragati.nic.in/

4. https://www.nationalskillsnetwork.in

5. https://www.cmie.com/ 